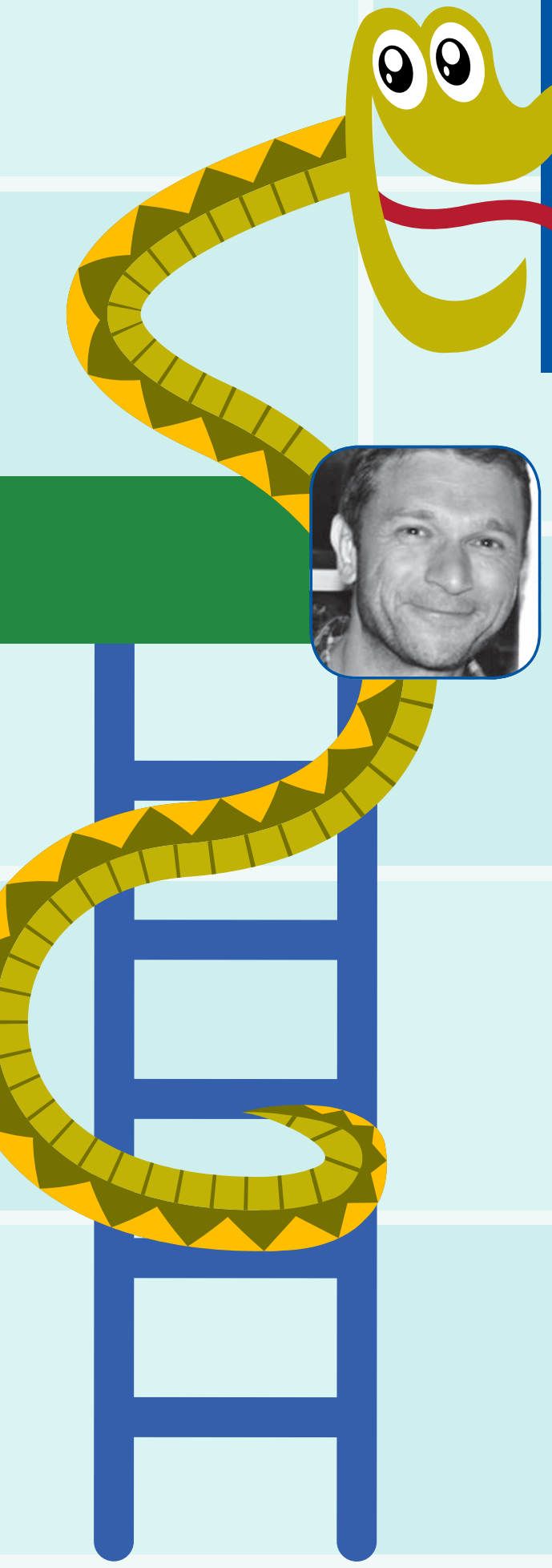

'Ben is an NHS dentist in York. His main areas of interest are preventative and minimally invasive dentistry. He began developing the Brush DJ app and videos in 2011 and has gone on to win a number of awards, becoming one of the inaugural fellows on the NHS Innovation Accelerator programme. The programme supports exceptional individuals with a passion for learning and a commitment to share their learnings widely, scaling evidence-based innovations for greater patient benefit https://www.england. nhs.uk/ourwork/innovation/nia/.

\title{
The smakes
}

\section{and ladalers of innovation in dentistry}

\author{
Do you have an idea that you think would \\ really make a difference in dentistry? Then Ben
}

Underwood, ${ }^{1}$ a dentist and NHS Innovation

Accelerator Fellow, can help.

\section{Innovation}

One of the best examples of a recent innovation is the smartphone. This has revolutionised the way people communicate, for example with WhatsApp, and how people find love, with apps such as Tinder. An innovation is a significant positive change from what existed before. It is important to distinguish that to be an innovation, rather than an invention, something needs to be widely adopted.

In dentistry there have been a number of revolutionary innovations - one example is the ability to bond to enamel and dentine, which allows material to be attached rather than just be passively held in or on teeth. Bonding also revolutionised orthodontics, allowing the use of brackets. Another example is the air turbine, which replaced the electric and pedal drills.

An innovation can be a new way of working as well as a physical or digital product.

\section{Snakes and Ladders}

Snakes and Ladders is a board game that most people will have played as a child. Players start at the bottom of the board and the victor is the one who gets to the top first. On the way to the top are a number of snakes and ladders connecting two squares.

The snakes can hinder progress, sending the player down the board, and the ladders can help, allowing the player to skip a number of squares to move higher up the board. This journey to the top makes Snakes and Ladders a good analogy for innovation. The inventor, whether that is an individual or organisation, wants their invention to be the one that gets to the top of the board before its competitors. In the case of dental innovations, to be the invention that gets widely used either by dental professionals or patients or the public: becoming an innovation. Whilst luck plays a part in any successful innovation there are a number of other helps (ladders) and hindrances (snakes) that can be encountered on the journey.

\section{The path from invention to innovation}

I will give a few examples of the snakes and ladders I have encountered during the development of the Brush DJ app. This app plays two minutes of music to motivate people, especially children, to brush for an effective length of time. The app also communicates via text and animated video the information for patients given in the Public Health England toolkit Delivering better oral health. To date the app has had over a quarter of a million downloads in 193

countries.

\section{People}

People are in my opinion the most

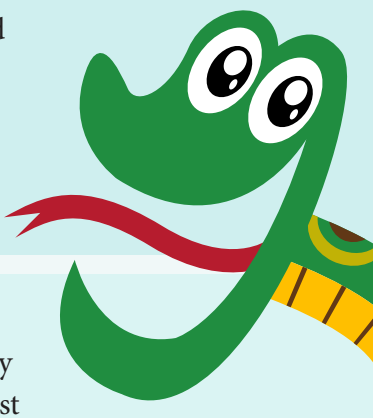

important factor in helping or

hindering an invention becoming an innovation. On my journey I have encountered both snakes and champions who will not only supply the ladders, but also hold them. The reason why some people will hinder is often due to fear.

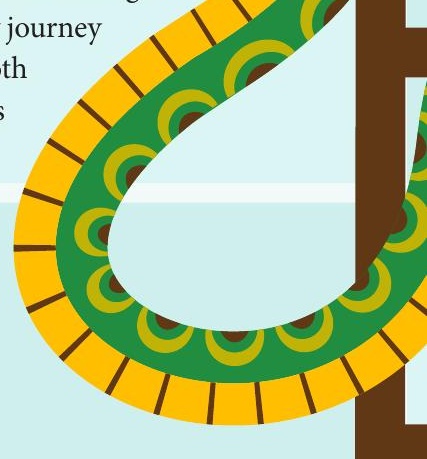




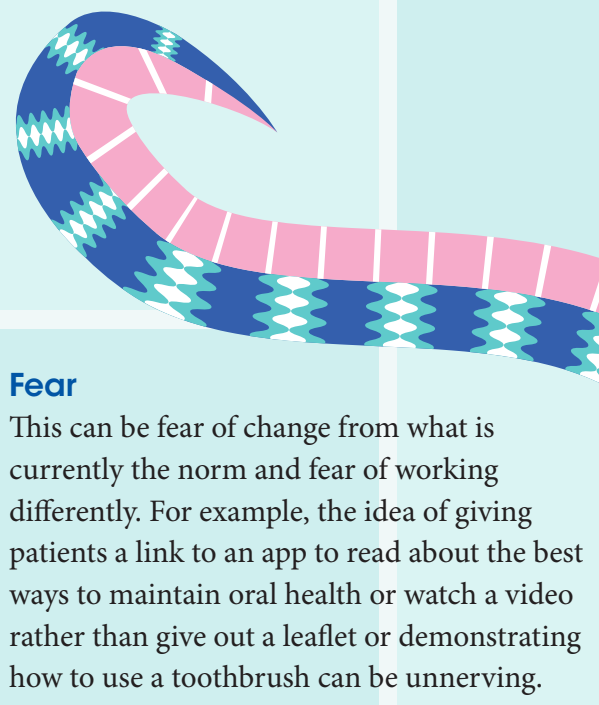

\section{Status quo (not the band!)}

People are more comfortable sticking with the way things are and they are used to - it requires less effort and time. The danger with this is getting stuck in a rut, which can be demoralising in the long-term and may not keep up with patient expectations.

\section{Regulation}

In healthcare we are quite rightly highly regulated because we are dealing with health and the potential to cause harm. The problem with regulation is when it stifles innovation because a new product does not fit into an existing regulatory pathway - this is especially true of digital products.

\section{Digital confidence}

A survey by Ofcom reported that digital confidence is highest among teenagers, but then drops gradually as age increases. A personal lack of confidence with digital products may act as a barrier to dental professionals recommending technological oral health tools such as apps and watching videos, because it is a way of learning they are not comfortable with and have grown up using.

\section{Evidence}

Another reason why apps might not be recommended is because of a lack of randomised controlled trials (RCTs)
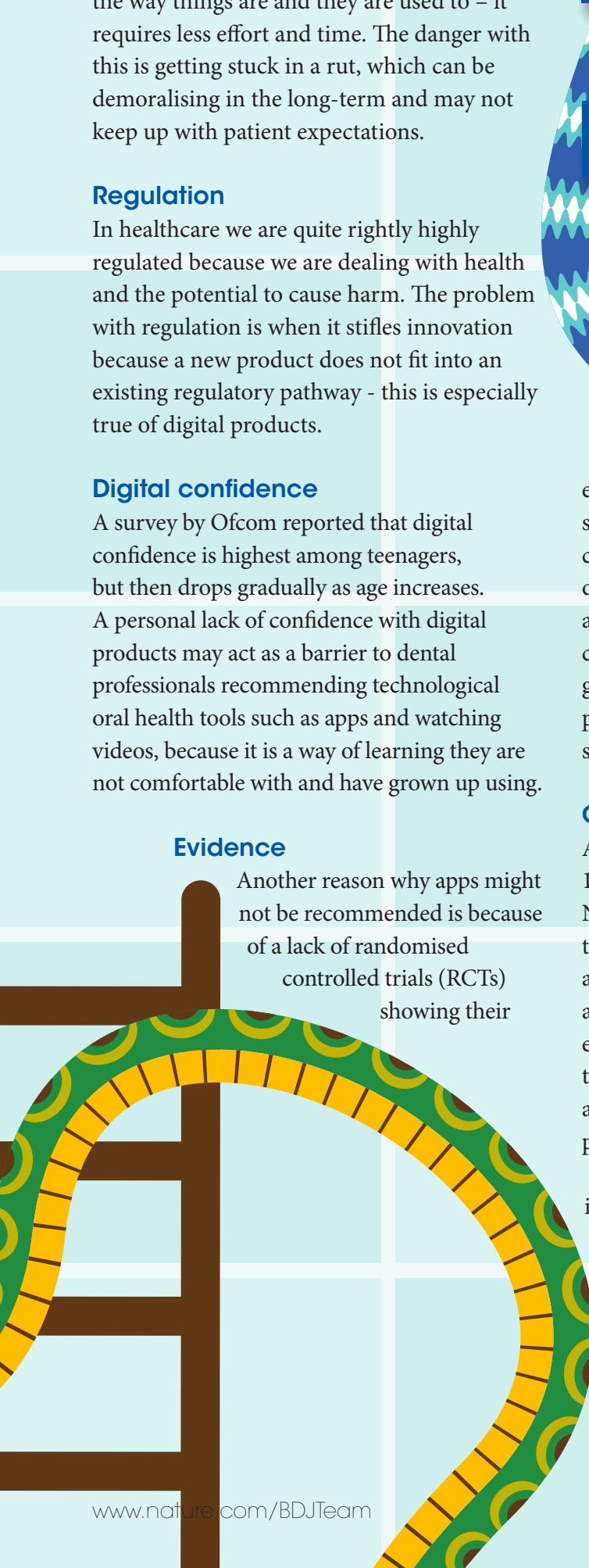

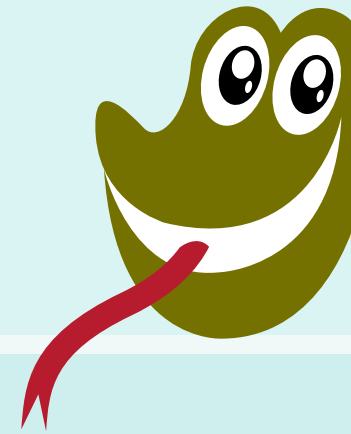

FEATURE

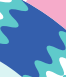

$\sqrt{3}$

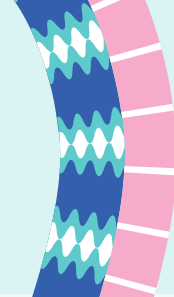

'IT IS IMPORTANT TO DISTINGUISH THAT

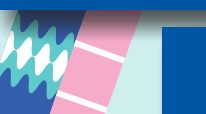

TO BE AN INNOVATION, RATHER THAN AN

\section{INVENTION, SOMETHING NEEDS TO}

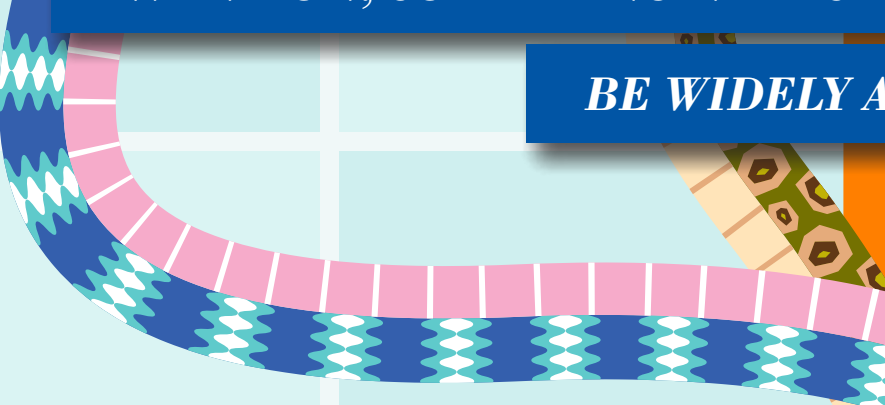

effectiveness. Whilst RCTs represent the gold standard of evidence they are expensive to carry out and are only of value if very well designed and free from bias. A more pragmatic approach is often required looking at risk and cost effectiveness - especially given the current financial pressures in the health service and wider economy.

\section{Getting help}

Around England there are

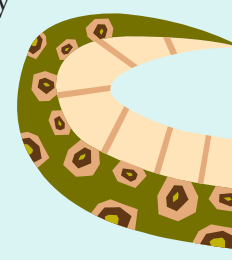
15 Academic Health Science

Networks (AHSNs) that can help you navigate the innovation process from invention to adoption - minimising the impact of snakes and maximising the ladders. There is an excellent free tool that people can use to guide them through the key questions they need to ask at different stages in the journey http:// pathwaytoinnovation.co.uk/.

In Scotland the equivalent to the AHSNs is the SHIL http://www.shil.co.uk/; in Wales

Health Innovation Cymru Wales https:// www.lifescienceshubwales.com/news/newscheme-launched-to-foster-healthcareinnovation-in-wales/ and in Northern Ireland The Technology Transfer Office for Health and Social Care in Northern Ireland http://www.innovations.hscni.net/.

\section{BE WIDELY ADOPTED.}

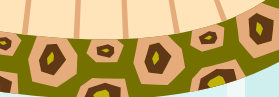

